\title{
Particle emissions from aircraft engines - a survey of the European project PartEmis
}

\author{
Andreas Petzold ${ }^{* 1}$, Markus Fiebig $^{1}$, Lutz Fritzsche ${ }^{1}$, Claudia Stein ${ }^{1}$, Ulrich \\ SCHUMANN $^{1}$, Chris W. Wilson ${ }^{2}$, Chris D. Hurley ${ }^{2}$, Frank ARnOld ${ }^{3}$, Eleni KatragKOU ${ }^{3}$, \\ Urs BAltensPerger ${ }^{4}$, MARTin GySEl ${ }^{4}$, StePhan Nyeki ${ }^{4}$, Regina Hitzenberger ${ }^{5}$, Hein- \\ Rich Giebl $^{5}$, Kevin J. Hughes ${ }^{6}$, Ralf Kurtenbach ${ }^{7}$, Peter Wiesen ${ }^{7}$, Paul Madden ${ }^{8}$, Hans \\ PUXBAUM $^{9}$, SUSi VRCHOTICKY ${ }^{9}$ and Claus WAHL ${ }^{10}$
}

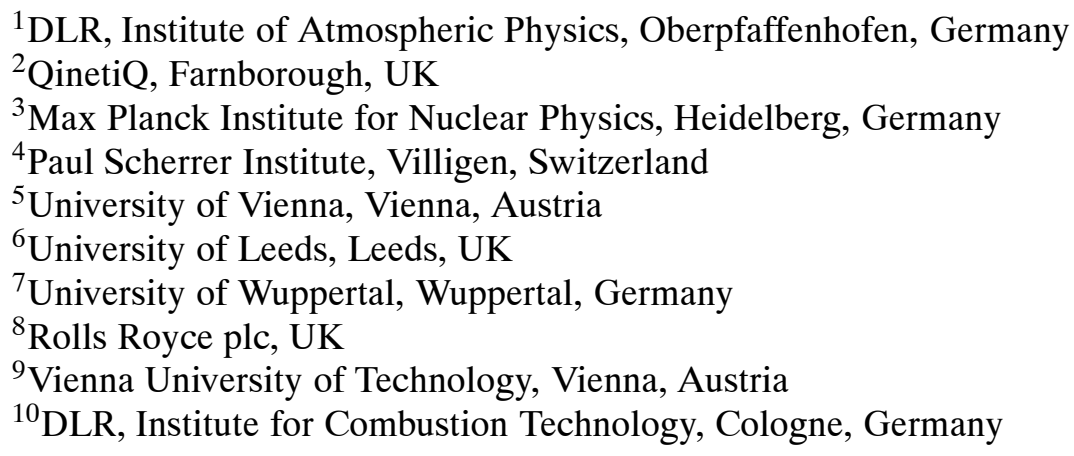

(Manuscript received January 20, 2004; in revised form September 3, 2004; accepted November 4, 2004)

\begin{abstract}
An overview of the goals and achievements of the European PartEmis project (Measurement and prediction of emissions of aerosols and gaseous precursors from gas turbine engines) is presented. PartEmis was focussed on the characterisation and quantification of exhaust emissions from a gas turbine engine. The engine was composed of a combustor and a unit to simulate a 3-shaft turbine section (so-called Hot End Simulator; HES). A comprehensive suite of aerosol, gas and chemi-ion measurements were conducted under different, i) combustor and HES operating conditions, ii) fuel sulphur concentrations. Measured aerosol properties were mass and number concentration, size distribution, mixing state, thermal stability of internally mixed particles, hygroscopicity, cloud condensation nuclei $(\mathrm{CCN})$ activation potential, and chemical composition. Furthermore, chemi-ions, non-methane volatile organic compounds (NMVOCs) and $\mathrm{OH}$ were monitored. The combustor operation conditions corresponded to modern and older engine gas path temperatures at cruise altitude, with fuel sulphur contents (FSC) of $0.05,0.41$, and $1.270 \mathrm{~g} \mathrm{~kg}^{-1}$. The combustor behaved like a typical aircraft engine combustor with respect to thermodynamic data and main emissions, which suggests that the PartEmis database may be applicable to contemporary aircraft engines. The conclusions drawn from the PartEmis experiment are discussed separately for combustion particles, ultrafine particles, sulphate-containing species and chemi-ions, particle hygrioscopic growth and $\mathrm{CCN}$ activation, gaseous organic fraction, and emission properties.
\end{abstract}

\begin{abstract}
Zusammenfassung
Die in dem europäischen Projekt PartEmis (Messung und Modellierung der Emissionen von Partikeln und gasförmigen Vorläufern aus Gasturbinen) erzielten Ergebnisse werden vorgestellt. PartEmis konzentrierte sich auf die Charakterisierung und Quantifizierung von Abgasemissionen aus einer Gasturbine. Das Triebwerk bestand aus einer Brennkammer und einer Einheit zur Simulierung einer 3-stufigen Turbinensektion, dem so genannten Hot End Simuator. Ein umfassendes System zur Messung von Aerosolen, Gasen und Ionen wurde i) unter verschiedenen Betriebsbedingungen der Brennkammer und des Hot End Simulators, und ii) bei verschiedenen Schwefelgehalten im verwendeten Treibstoff eingesetzt. Die gemessenen Aerosoleigenschaften umfassten Massen- und Anzahlkonzentration, Größenverteilung, Mischungszustand, thermische Stabilität intern gemischter Partikel, Hygroskopizität, Aktivierbarkeit zur Bildung von Wolkentropfen, und chemische Zusammensetzung. Weiterhin wurden Chemi-Ionen, Nicht-Methan Kohlenwasserstoffe (NMVOC) und OH gemessen. Die Betriebsbedingungen der Brennkammer entsprachen den Gaseintrittstemperaturen alter und moderner Triebwerke in Reiseflughöhe. Der Schwefelgehalt im Treibstoff variierte von 0,05 über 0,41 bis $1,270 \mathrm{~g} \mathrm{~kg}^{-1}$. Die Brennkammer verhielt sich im Bezug auf thermodynamische Daten und Emissionsdaten wie die typische Brennkammer eines Flugzeugtriebwerks. Davon ausgehend lassen sich die erreichten Ergebnisse auf moderne Flugzeugtriebwerke übertragen. Die Schlussfolgerungen aus dem PartEmis Experiment werden getrennt für Verbrennungspartikel, ultrafeine Partikel, sulfathaltige Komponenten und Chemi-Ionen, Feuchtewachstum der Partikel und Aktivierbarkeit zu Wolkentropfen, gasförmige organische Verbindungen und Emissionseigenschaften der Brennkammer diskutiert.
\end{abstract}

${ }^{*}$ Corresponding author: Andreas Petzold, DLR Institute of Atmospheric Physics, Oberpfaffenhofen, 82234 Wessling, Germany, e-mail: andreas.petzold@dlr.de 


\section{Introduction}

The role of aviation-related particle emissions in the upper troposphere and lowermost stratosphere is a matter of concern, particularly with respect to a possible effect on the composition of upper tropospheric aerosol and the life cycle of cirrus clouds (BOUCHER, 1999; SCHUMANN and STRÖM, 2001). Despite recent considerable progress in the characterisation of the aerosol particles emitted from aircraft engines (e.g., ANDERSON et al., 1998; Brock et al., 2000; HAGEN et al., 2001; PETZOLD and SCHRÖDER, 1998; PETZOLD et al., 1999; SCHUMANN et al., 2002), microphysical and chemical properties as well as the influence of engine operating conditions still remain poorly characterised with respect to particulate emissions. However, this kind of data set forms a basic pre-requisite for modelling approaches which investigate the role of aviation aerosols in the physics and chemistry of the upper free troposphere and lowermost stratosphere and their effect on earth's climate.

In the framework of the European project PartEmis ("Measurement and prediction of emissions of aerosols and gaseous precursors from gas turbine engines"), the influence of operation conditions and fuel sulphur content (FSC) on the microphysical and chemical properties of particles emitted from an aircraft engine simulator was investigated. For these purposes, an engine simulator which met the ICAO (International Civil Aviation Organisation) engine emissions smoke standard was operated on a test rig at the QinetiQ (formerly Defence Evaluation and Research Agency DERA) test site at Pyestock, UK. This engine simulator consisted of a real aircraft engine combustor and a so-called Hot End Simulator (HES) which simulates the pressure and temperature profiles found in an aircraft engine turbine section. In a first experiment in February 2001, the emission properties of the combustor were studied. These data were analysed and used as boundary conditions

Table 1: Combustor operating conditions during the 2001 Combustor and 2002 HES campaigns.

\begin{tabular}{lllll}
\hline $\begin{array}{l}\text { Combustor } \\
\text { Parameters }\end{array}$ & \multicolumn{2}{c}{ Combustor Campaign } & \multicolumn{2}{l}{ HES Campaign } \\
\hline & Old & Modern & Old & Modern \\
\hline $\begin{array}{l}\text { T combustor } \\
\text { inlet, K }\end{array}$ & 566 & 766 & 566 & 760 \\
$\begin{array}{l}\text { T combustor } \\
\text { outlet, K }\end{array}$ & 1125 & 1448 & 1125 & 1360 \\
$\begin{array}{l}\text { P combustor } \\
\text { inlet, 10 }\end{array}$ & 7.05 & 8.2 & 7.05 & 8.2 \\
$\begin{array}{l}\text { Air mass flow, } \\
\text { kg s }{ }^{-1}\end{array}$ & 2.12 & 2.12 & 1.90 & 2.05 \\
$\begin{array}{l}\text { Fuel flow, } \\
\text { kg s }-1\end{array}$ & 0.032 & 0.042 & 0.030 & 0.035 \\
Air fuel ratio & 66 & 50.3 & 66 & 58 \\
\hline
\end{tabular}

for a second experiment in March/April 2002, which focused on the emission properties of the combustorHES combination. Fig. 1 shows a schematic of the combustor-HES combination, including the sample extraction points used during the combustor experiments in 2001 and the HES experiments in 2002.

The aerosol microphysical and chemical properties investigated in this study covered number, size, and mass concentration of combustion aerosol particles and of volatile condensation particles. Furthermore, the volatile fraction of internally mixed combustion particles, particle hygroscopicity, and cloud condensation nuclei $(\mathrm{CCN})$ activation potential were studied. In addition, the emission of chemi-ions, non-methane volatile organic compounds (NMVOCs) and $\mathrm{OH}$ was monitored. A detailed description of the PartEmis experiments is given by WILSON et al. (2004).

\section{Methods}

A tubo-annular, transpiration cooled combustor was chosen for tests on QinetiQ's High Pressure Combustion Rig. The combustor did not represent a particular type of aircraft engine technology. Although the combustor is based on a 30-year old design, it has been substantially modified with new cooling and fuel injection systems according to current legislation and technological advances such that it meets the emissions requirements of modern civil combustors. In the actual engine itself, ten of these combustors would be circumferentially spaced around the engine core. The exit nozzle used was a $36^{\circ}$ "smile" shaped discharge nozzle, as employed in the engine. Air was delivered from a four-stage compressor and heater unit. For all investigated compounds and aerosols the concentration levels in the inlet air were determined and subtracted from the measured results, if applicable. A back-pressurising valve located downstream of the combustor maintained the correct pressure in the system. After extraction of sample exhaust at the combustor exit, the remainder of the high-temperature exhaust gases were cooled using water injection via a set of spray-bars. The standard test-rig instrumentation covered control parameters, such as temperature, pressure, fuel and air flow rates, as well as $\mathrm{CO}, \mathrm{CO}_{2}$, total hydrocarbons ( $\mathrm{HC}), \mathrm{NO}_{X}$, and smoke number. For more details on the technical set-up of the test rig and on operation conditions, see WILSON et al. (2004).

Two engine operating conditions were simulated to represent the thermodynamic conditions found in the turbine stages of legacy referred to here as "old" and modern aircraft cruise conditions at 35,000 feet ( $\sim 11,700 \mathrm{~m})$. This will ensure that the conversion of fuel sulphur to oxidised sulphur species is replicated. These old and modern combustor operating conditions were also chosen to meet the ICAO smoke emission 


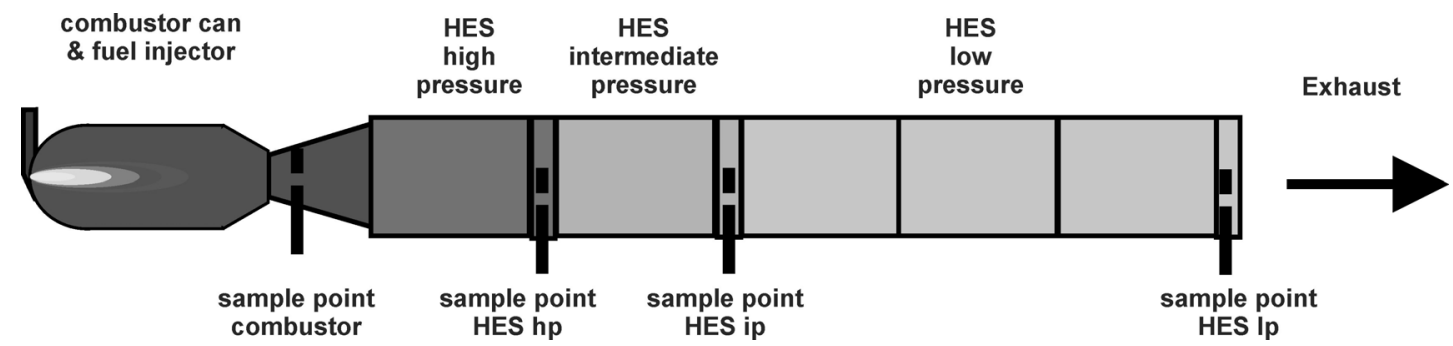

Figure 1: Schematic of the PartEmis combustor and Hot End Simulator HES; the HES is composed of three separate heat exchanger stages, referred to as high (hp), intermediate (ip) and low pressure (lp) stages.

Table 2: Available equipment and parameters.

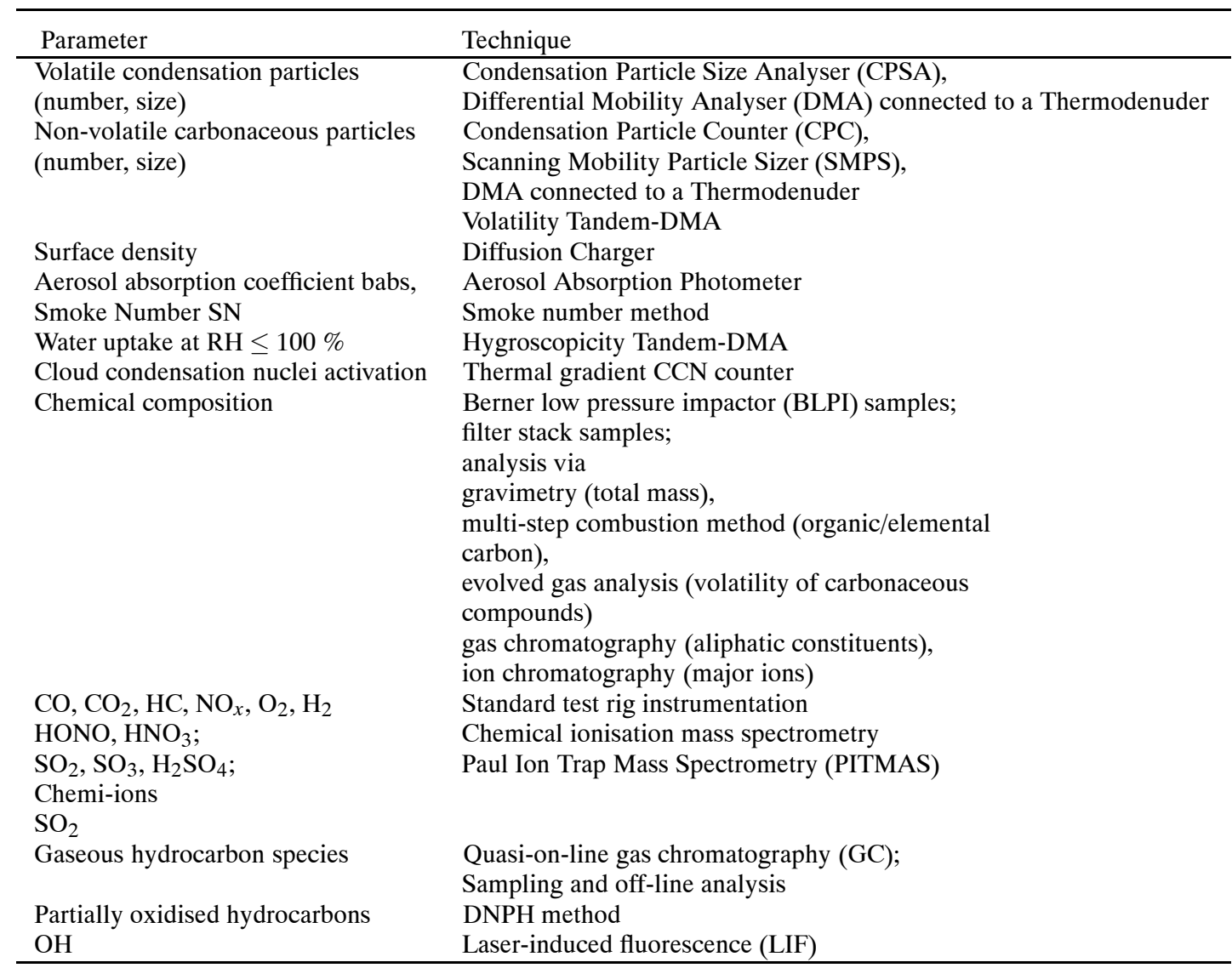

level. Fuel sulphur content (FSC) levels covered the range from low sulphur fuel $\left(0.05 \mathrm{~g} \mathrm{~kg}^{-1}\right)$ to the contemporary average $\left(0.41 \mathrm{~g} \mathrm{~kg}^{-1}\right)$ and to a maximum of about three times this average $\left(1.270 \mathrm{~g} \mathrm{~kg}^{-1}\right)$ defined here as Low, Mid and High (L, M, H) FSC, respectively. The sulphur content was varied by adding known quantities of benzenethiol $\left(\mathrm{C}_{6} \mathrm{H}_{5} \mathrm{SH}\right)$ to the low FSC fuel. The operation conditions are summarised in Table 1.

The employed aerosol measurement methods consisted of various size-selective methods, aerosol absorption photometers, thermodenuder methods, a Cloud Condensation Nuclei (CCN) Counter (Hitzenberger et al., 2003a), an extensive set of chemical analytical methods (PETzOLD et al., 2003a, PUXBAum et al., 2003), mass spectrometry methods for the detection of sulphur-containing species, and laser-induced fluores- cence for $\mathrm{OH}$ measurements. A summary of deployed methods is given in Table 2 .

The black carbon (BC) mass concentration and the aerosol absorption coefficient in the diluted sample gas were measured using a Particle Soot Absorption Photometer (PSAP; Radiance Research Inc, Seattle, USA). The specific absorption cross section at $\lambda=0.55 \mu \mathrm{m}$, $\sigma_{a b s}=6.7 \mathrm{~m}^{2} \mathrm{~g}^{-1}$ was used for conversion of light absorption to BC mass. The particle number concentrations were measured in the size intervals $D=4-7$ $\mathrm{nm}, 7-9 \mathrm{~nm}, 9-20 \mathrm{~nm}$, and 20-250 nm with paralleloperated condensation particle counters (Condensation Particle Size Analyser, CPSA) which were set to different lower instrument cut-off diameters. Particles of size $D>9 \mathrm{~nm}$ which are detected in CPSA channels 3 and 4 , are in the following referred to as $N_{10}$. Particle size 
distributions were measured with a commercial Scanning Mobility Particle Sizer (SMPS; TSI Model 3071) and a Volatility-Tandem Differential Mobility Analyser (V-TDMA) in the size range $D>13 \mathrm{~nm}$.

The aerosol mixing state and the volatile fraction of the combustion aerosol were determined using thermal denuder methods which differentiate particles by number according to their thermal stability. As was investigated in previous calibration experiments, thermal denuder temperatures of $390 \mathrm{~K}$ and 573-625 K, respectively, distinguish volatile (vaporises at $390 \mathrm{~K}$ ) sulphuric-acid like material from semivolatile (vaporises between 390 and $573 \mathrm{~K}$ ), and refractory black-carbon like material. The thermal treatment of almost monodisperse particle size fractions which were pre-selected by a DMA provides information whether the aerosol is internally or externally mixed. The ratio of diameters after and before thermal treatment yields the particle shrinkage factor $D_{2}^{3} / D_{0}^{3}$. This factor describes the particle volume reduction by the thermal treatment, i.e., the volatile volume fraction of internally mixed particles is $1-D^{3} / D_{0}^{3}$.

The hygroscopic particle growth factor under subsaturated conditions was measured with a Hygroscopicity Tandem DMA (GYSEL et al., 2002, 2003a) During the measurements, the instrument was kept at a constant temperature of $\mathrm{T} \cong 298 \mathrm{~K}$. The obtained hygroscopic growth factor describes the particle growth by water uptake from the gas phase at a selected relative humidity. Measurements were performed in the relative humidity range from 70 to approximately $95 \%$. As was demonstrated by GYSEL at al. (2002, 2003a) from KoEHLER theory, the hygroscopic growth factor of a particle is a function of dry particle size, relative humidity, and particle coating with a water-soluble substance. For the PartEmis experimental data, the coating substance was sulphuric acid. The magnitude of the particle growth at a given relative humidity and for a given size of the dry particle can be directly linked to volume fraction of water-soluble matter contained in the investigated particles. During the PartEmis experiments, the hygroscopic growth factors measured for fixed dry particle sizes but variable fuel sulphur contents, were used for the determination of the coating of the combustion aerosol by sulphuric acid. The number of particles which become finally activated as cloud condensation nuclei in the case of water-supersaturation were measured with a static thermal diffusion chamber CCN counter (GIEBL et al., 2002). The instrument was operated at a supersaturation ratio of $0.6-0.7 \%$ with respect to liquid water. The activation ratio or fraction of $\mathrm{CCN}$ activated particles, respectively, was determined as the ratio of the number of activated $\mathrm{CCN}$ to the number of total particles (Hitzenberger et al., 2003a). The ability of combustion particles for taking up water from the gas phase is a key property in the formation processes for liquid water clouds. However, it is also of relevance for jet condensation trail formation (SCHUMANN, 1996), and it may as well play a role in the formation of ice nuclei from combustion particles (DEMOTT et al., 1999).

Aerosol samples were collected with filter stack samplers and low pressure Berner impactors for total aerosol and size-resolved chemical mass analysis (PUXBAUM et al., 2003). The chemical composition of the carbonaceous fraction of the exhaust particles was determined using multi-step combustion methods. Total carbon (TC) was determined by a combustion technique involving combustion in a vertical furnace and detection of $\mathrm{CO}_{2}$ with a commercial NDIR (non dispersive Infrared spectrometer) unit. Aliquots of a collected filter sample were burnt in the ceramic tube of a combustion furnace with an excess of oxygen at a temperature of $1000^{\circ} \mathrm{C}$. Elemental carbon (EC) was determined by the "Cachier" method (CACHIER et al., 1989), i.e., another aliquot of the filter sample was treated for $2 \mathrm{~h}$ at $320^{\circ} \mathrm{C}$ in an oxygen atmosphere to remove organic carbon compounds and then analysed with the same TC analysis method. The remaining carbon was attributed to elemental carbon (EC). Thermograms of the collected carbonaceous material were measured with a thermo-optical evolved gas analysis method (SCHMID et al., 2001). To determine anions, e.g., $\mathrm{SO}_{4}^{2-}$, as well as cations, two Dionex isocratic systems with electrochemical suppression were used.

In addition, the aerosol was sampled on quartz tubes containing glass wool. The aerosol loaded quartz tubes were analysed by $5 \mathrm{~min}$ thermodesorption in a Helium atmosphere at $130^{\circ} \mathrm{C}$ and $350^{\circ} \mathrm{C}$, respectively. The desorbed $\mathrm{C}_{2}-\mathrm{C}_{12}$ non-methane hydrocarbons (NMHC) were analysed with a gas chromatograph (GC; Hewlett Packard). NMHCs were monitored using a compact GC instrument (Airmovoc 2010) with a cryotrap as an enrichment system and a flame ionisation detector. C2$\mathrm{C} 10$ aliphatic and aromatic NMHCs were measured with a time resolution of $10 \mathrm{~min}$ and with detection limits in the pptv range. Selected partially oxidised hydrocarbons (OHC) such as carbonyl compounds and organic acids were collected by using commercial sampling cartridges coated with 2,4-Dinitrophenylhydrazine. This chemical compound forms with the carbonyl molecules a stable compound called hydrazone. This hydrazone is stable for weeks and can be analysed later in the Laboratory. To analyse the carbonyl compounds, the hydrazones are rinsed out of the cartridge and separated in a High Performance Liquid Chromatograph HPLC. The OHC were measured with a time resolution of $4 \mathrm{~min}$ and with detection limits in the ppbv range. All hydrocarbon compound measurements were corrected for line losses and background values. 

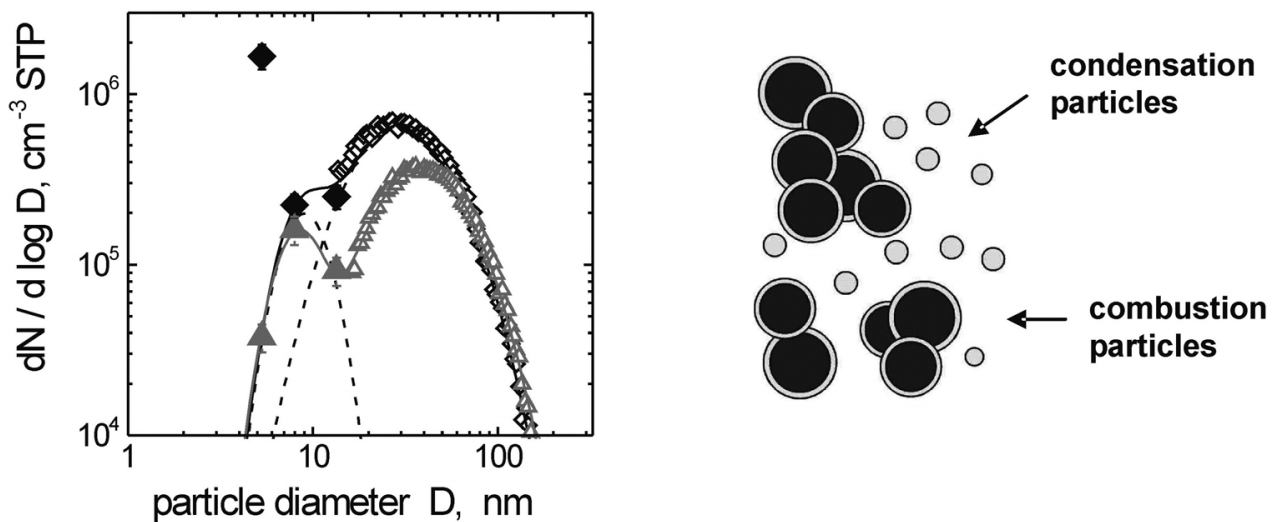

Figure 2: Left: size distribution of combustion aerosol with (diamonds) and without condensation particle formation (triangles). Right: External aerosol mixture composed of volatile condensation particles (grey) and coated nonvolatile combustion particles (black).

Gaseous sulphuric acid was measured using a CIMS (Chemical Ionisation Mass Spectrometer) apparatus equipped with an Ion Trap Mass Spectrometer (ITMS). The CIMS apparatus comprises a stainless steel flow reactor (inner diameter $4 \mathrm{~cm}$, total length $164 \mathrm{~cm}$ ) heated up to $80 .{ }^{\circ} \mathrm{C}$, a high frequency glow discharge ion source for reagent ion production and a Quadrupole Ion Trap Mass Spectrometer for ion detection. The ITMS allows CID (Collision-Induced-Dissociation) investigations of mass selected ions to be performed which in turn allows much better species identification than can be offered by a conventional mass spectrometer. Reactant ions of the type $\mathrm{NO}_{3}\left(\mathrm{HNO}_{3}\right)_{n}(\mathrm{n}=0,1,2)$ are produced in a separate chamber where a high frequency gas discharge burns in a buffer gas of $\mathrm{O}_{2}$ and $\mathrm{NO}_{2} / \mathrm{N}_{2}$ and injected into the flow reactor upstream of the ion sampling orifice of the Mass Spectrometer. After injection ions are carried by the gas stream to the mass spectrometer. When gaseous sulphuric acid is present in the flow reactor some fraction of the reagent ions reacts via a gas phase ion molecule reaction with sulphuric acid. By measuring the abundance ratio of product and reagent ions the gaseous sulphuric acid concentration in the flow reactor is determined. For more details see KATRAGKOU et al. (2004) and references given there.

$\mathrm{OH}$ laser induced fluorescence (LIF) measurements were performed in the exhaust duct of the HES. The experiment comprised a Nd/YAG pumped dye laser set up to generate light at $\lambda=281.913 \mathrm{~nm}$ in order to excite the $\mathrm{Q}_{1}(1)$ transition of $\mathrm{OH} \mathrm{A}^{2} \Sigma\left(v^{\prime}=1\right) \leftarrow X^{2} \Pi\left(v^{\prime \prime}=0\right)$, chosen as it is one of the strongest transitions at the temperature expected at the observation point. Fluorescence was detected perpendicular to the path of the laser from the $v^{\prime}=0 \rightarrow v^{\prime \prime}=0$ transition around $309 \mathrm{~nm}$ via a lens and a customised interference filter. In order to maximise the signal to noise ratio by discriminating against Raman scatter expected from $\mathrm{N}_{2}$ and $\mathrm{H}_{2} \mathrm{O}$, an interference filter was centred at $308.75 \mathrm{~nm}$ with a band pass of $4.96 \mathrm{~nm}$. A gated $\mathrm{CCD}$ camera cooled to $-30^{\circ} \mathrm{C}$ was used to collect the signal, allowing signal accumulation over long times in order to enhance sensitivity.

Since the full set of applied instruments was connected to separate sampling lines according to specific instrument requirements, the precise determination of the dilution factors was a crucial task. After exit from the traversing probe, the sample was cooled to $\sim 150^{\circ} \mathrm{C}$ using a water-jacket, and delivered to the undiluted and diluted sample lines. The undiluted line was insulated along its entire length in order to avoid cooling and therefore wall losses of less volatile combustion products. A detailed description of the extracting probe and the sample transportation system is given in WILSON et al. (2004). Dilution with filtered air was necessary for the majority of instruments to reduce concentrations down to a measurable level. The sample dilution factor was determined from $\mathrm{CO}_{2}$ mixing ratios measured in the supplied dilution air, diluted sample, and undiluted sample, as well as from temperature and pressure sensors throughout the sample delivery system. The average dilution factor was 65 (PETZOLD et al., 2003a).

Although stable gaseous species such as $\mathrm{CO}_{2}$ and water vapour are unaffected by intrusive sampling, aerosols may be lost due to diffusion and sedimentation to the surfaces of the sampling system. Estimates of expected line losses were obtained from experiments (HURLEY, 1996) performed with aerosol generated by a spark discharge generator (PALAS GfG 1000). The aerosol was fed into sample lines of different cross section and length and the sample flow through the lines was varied. From these studies, expected line losses are $<20 \%$ by number of particles for the conditions during the PartEmis experiments. Since line losses affect predominantly small particles $<20 \mathrm{~nm}$ in diameter, the aerosol mass is assumed to be almost unaffected by line losses. However, the values given for emission indices have to be taken as upper values. Size distributions reported for combustion particles cover a size range of 10 $250 \mathrm{~nm}$. The size spectra used for the investigation of the 
impact of operation conditions and fuels sulphur content were not corrected for line losses, because corrections are similar for all test points. Thus, relative trends concerning the influence of fuel sulphur and operation conditions on the microphysical properties of the emitted particles are not affected by line losses. Because of the observed size range of exhaust particles, count median diameters and geometric standard deviations of measured size distributions are also expected to be only marginally influenced by line losses.

\section{Results}

\subsection{Microphysical properties}

The aerosol emitted from the Combustor is composed of primary particles forming inside the combustor and of volatile condensation particles nucleating in the cooling exhaust gas from gaseous precursors. The aerosol size distribution in the diluted exhaust gas of the combustor is shown in Fig. 2 for conditions with and without condensation particle formation. While the mode of combustion aerosol particles dominates the size range $D>15 \mathrm{~nm}$ with a maximum at $40 \mathrm{~nm}$, another mode of nanoparticles is present in all cases in the size range $D=7-20 \mathrm{~nm}$. Condensation particle formation, is occurring only at high FSC conditions and contributes to the size range $D=4-7 \mathrm{~nm}$.

The emission properties with respect to the primary aerosol are shown in terms of $\mathrm{BC}$ mass $\left(E I_{B C}\right)$, TC mass $\left(E I_{T C}\right)$, and number $\left(E I_{N 10}\right)$, emissions per $\mathrm{kg}$ of consumed fuel in Fig. 3. The number emission index $E I_{N 10}$ refers to particles with diameters $D \geq 10 \mathrm{~nm}$. In Fig. 3, also the count median diameter (CMD) of the exhaust aerosol size distribution is shown. Plotted are corresponding values for the combustor emissions and emissions from the HES low pressure stage. In the first place, it has to be mentioned that all the results are consistent. At old cruise conditions, an increasing number emission at constant black carbon mass emission is balanced by a decreasing particle size with respect to the particle electrical mobility diameter. It should be noted that these results originate from different measurement techniques.

When operated at old engine conditions with low combustor inlet temperature $T_{C}, E I_{B C}$ varies from 0.051 to $0.081 \mathrm{~g} \mathrm{~kg}^{-1}$. Operated at modern engine conditions with the higher inlet temperature, $E I_{B C}$ ranges from 0.028 to $0.044 \mathrm{~g} \mathrm{~kg}^{-1}$ which is a factor of two lower. Similar relations hold for the other properties. However, the amount of emitted particulate matter is within the range permitted by the ICAO rules in all cases. All particle emission indices referring to number and mass are in close agreement with values obtained from inflight measurements which span a range from $0.5-0.75$

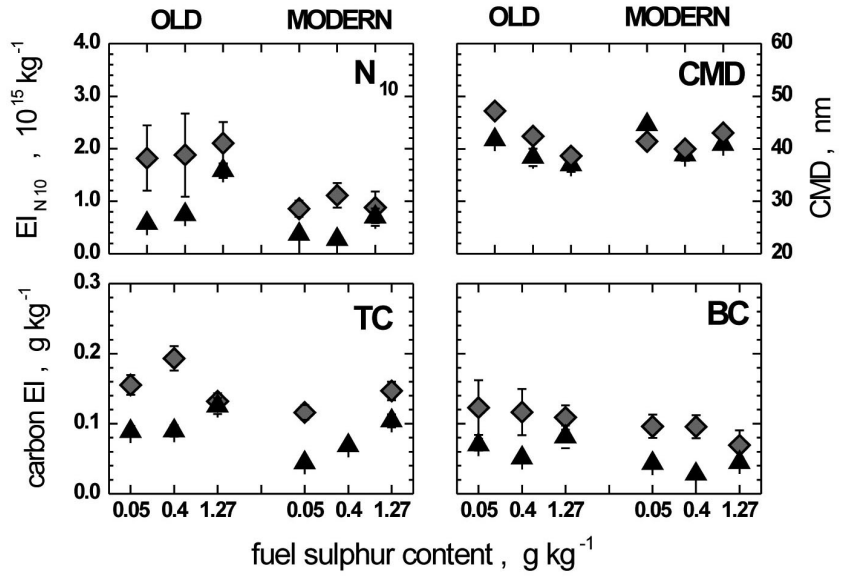

Figure 3: Emission indices in terms of number $\left(N_{10}\right)$, total carbon mass (TC), black carbon mass (BC) and count median diameter (CMD) of the combustion aerosol for the Combustor exit (triangles) and the Hot End Simulator low pressure stage (diamonds); values are given for old and modern operation conditions as a function of the fuel sulphur content, error bars indicate signal variability in terms of \pm 1 stdev.

$\mathrm{g} \mathrm{kg}^{-1}$ for a Boeing B707 to $0.01 \mathrm{~g} \mathrm{~kg}^{-1}$ for Airbus A 340 and Boeing B737 equipped with CFM 56 series engines (SChUMANN et al., 2002; PetzOLD et al., 2003a, 2003b). The fleet-averaged mass emission index of $0.038 \mathrm{~g} \mathrm{~kg}^{-1}$ (PETZOLD et al., 1999) lies within the range of values determined for modern operation conditions.

Mean CMD values are 37-41 $\mathrm{nm}$ for old engine and 40-44 $\mathrm{nm}$ for modern engine conditions. The geometric standard deviation of the size distribution is 1.67 (1.6-1.8) for both operation conditions (PETZOLD et al., 2003a, 2003b). The combustor operating conditions have only a weak influence on the size, number and mass of emitted particles. Size distribution peaking at similar diameters were observed during several in-flight studies. HAGEN et al. $(1996,1998)$ reported peak diameters of 30-60 nm and size distribution widths of approx. 1.6. During the SULFUR studies (PETZOLD et al., 1999; SCHUMANN et al., 2002), peak diameters of $35 \mathrm{~nm}$ were observed. The PartEmis size distribution parameters are in close agreement with the reported in-flight observations.

The influence of the different HES pressure stages is demonstrated in Fig. 3 and with more detail in Fig. 4. As is shown in Fig. 3, the trends observed in particle emission properties in the combustor experiments with varying fuel sulphur content and operation conditions again observed during the HES experiments. Except for a step-like increase from the combustor experiments to the HES experiments which is most likely due to slightly different operating conditions, the HES has no influence on the emission properties of the Combustor-HES combination with respect to combustion aerosol particles, 


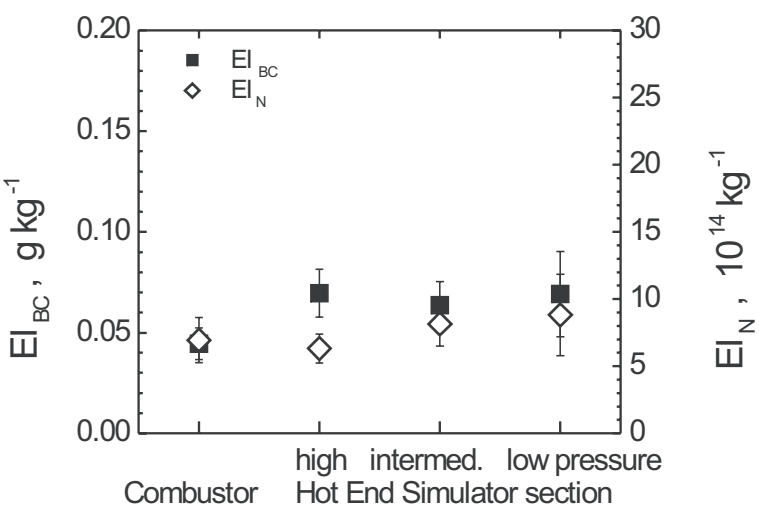

Figure 4: Effect of the Hot End Simulator on the emission properties of the Combustor-HES combination operated at modern conditions, error bars indicate signal variability in terms of \pm 1 stdev.

see Fig. 4. Increasing the FSC, slightly increases the total number of emitted particles.

Particles smaller than $10 \mathrm{~nm}$ contribute less than $10 \%$ to the total exhaust aerosol in the low and medium FSC cases. At high FSC levels the formation of volatile condensation particles with diameters $D<10 \mathrm{~nm}$ is observed (PETZOLD et al., 2003c). A kinetic model was used to investigate the nucleation efficiency of the $\mathrm{H}_{2} \mathrm{O}$ - $\mathrm{H}_{2} \mathrm{SO}_{4}$ binary mixture in the exhaust gas and the particle coagulation processes during the transport through the sampling system to the measurement instrumentation (VANCASSEL et al., 2004). The model confirmed that the condensation particles form at the dilutor of the sampling system. During combustion, the sulphur contained in the fuel is oxidised to $\mathrm{SO}_{2}$ which is then partially converted to $\mathrm{S}(\mathrm{VI})$ in the hot exhaust gas. The efficiency of conversion from $\mathrm{S}(\mathrm{IV})$ to $\mathrm{S}(\mathrm{VI})$ is described by the conversion efficiency calculated as $\varepsilon=\mathrm{S}(\mathrm{VI}) / \mathrm{S}_{T}$ where $\mathrm{S}_{T}$ is the total fuel sulphur. In the combustor exhaust the S(VI) increases with increasing FSC. In the kinetic model study, a value for the efficiency was indirectly deduced from comparisons between model results and measurements. In the PartEmis cases, $\varepsilon$ ranges between roughly $2.5 \%$ and $6 \%$, depending on the combustor settings and on the microphysical approach used. For these values which are close to results from direct measurements of gaseous sulphuric acid, the kinetic model reproduces the observation of volatile particles in the size range 4-7 $\mathrm{nm}$ for the high FSC case, while no volatile particles are found by the model for the low and medium FSC cases.

Particles of size $D \geq 30 \mathrm{~nm}$ are almost entirely internally mixed. Smaller particles $(D<20 \mathrm{~nm})$ exhibit volume fractions of $10-15 \%$ for volatile and $4-10 \%$ for semi-volatile material, while the volatile fraction decreases to $<5 \%$ for $D \geq 50 \mathrm{~nm}$ particles (PETZOLD et al., 2003a; NYEKI et al., 2003). The decrease of the volatile particle fraction with increasing particle size is also reproduced by the kinetic model for the $\mathrm{H}_{2} \mathrm{O}-$ $\mathrm{H}_{2} \mathrm{SO}_{4}$ binary mixture (VANCASSEL et al., 2004). These values are valid for the conditions met during PartEmis. If the dilution air is more humid and a higher dilution forces stronger formation of condensation particles, the condensation particles may grow to larger sizes. However, as was observed in a young aircraft plume at cruise conditions, condensation particles were also observed mainly in the size range $D<10 \mathrm{~nm}$ (SCHRÖDER et al., 2000), similar to the PartEmis results.

\subsection{Chemical properties}

Primary particles emitted from the combustor are predominantly composed of carbonaceous material (>95\%) and of water-soluble inorganic components. The carbonaceous material is composed of organic compounds and of elemental or black carbon. The organic compounds evaporate and oxidise at different temperatures and become classified according to this criterion. Compounds which evaporate at temperatures as low as $400 \mathrm{~K}$ are classified as semi-volatie OC, compounds evaporating, compounds evaporating up to $800 \mathrm{~K}$ are termed nonvolatile $\mathrm{OC}$, and the remainder is elemental carbon. Fig. 5 shows the thermal stability of an exhaust aerosol sampled during operation with low FSC fuel at modern conditions. In the applied version of evolved gas analysis (SCHMID et al., 2001) the blackness of the filter sample is recorded parallel to the heating of the sample. As is demonstrated in Fig. 5, the filter starts to become "white" again, as soon as the elemental or black carbon starts to oxidise. The evaporation and subsequent oxidation of OC compounds leaves the filter black. Thus, the onset of increasing filter transmittance is an additional measure for separating organic and elemental carbon. The application of this methods yields an average contribution of black carbon to total carbon of 40-80\%, depending on the combustion conditions (PUXBAUM et al., 2003). From an aerosol loaded glass wool sample more than 180 different NMHCs were desorbed under an Helium atmosphere. Only 0.4 wt $\%$ of the NMHCs were desorbed at $\mathrm{T} \leq 400 \mathrm{~K}$, whereas $99.6 \mathrm{wt} \%$ were desorbed at $\mathrm{T}=400-620 \mathrm{~K}$. This is in good agreement with the result of the thermogram in Fig. 5. Elemental (EC) or black carbon (BC), respectively, is chemically almost inert at low and moderate temperatures and thermally stable up to temperatures of about $700 \mathrm{~K}$.

As determined from direct measurements of gaseous $\mathrm{H}_{2} \mathrm{SO}_{4}$, the efficiency of conversion in the combustor exhaust ranges between $0.9 \pm 0.5 \%$ and $1.3 \pm$ $0.7 \%$ (KATRAgKou et al., 2004). In the HES exhaust S(VI) increases with increasing FSC, fuel flow, and from the high-pressure to the low-pressure HES stage. For $\mathrm{FSC}=1.270 \mathrm{~g} \mathrm{~kg}^{-1}$ the conversion efficiency 
is $2.3 \pm 1.2 \%$ at the low pressure stage for the modern cruise condition and $1.4 \pm 0.7 \%$ for the old cruise. The higher $\varepsilon$ observed for the modern cruise conditions suggests that modern engines have a larger $\varepsilon$ compared to old engines. Conversion efficiencies determined from in-flight data at cruise altitude gave values $0.4-4.5 \%$ (SCHUMANN et al., 2002), which is in good agreement with the PartEmis ground test values.

Chemical composition information was obtained from Berner low pressure impactor samples which were taken at a sample line temperature of $150^{\circ} \mathrm{C}$ (PUXBAUM et al., 2003). At these conditions most of the sulphuric acid remains in the gas phase, while only a small fraction is more strongly bound to or chemi-sorbed at the particle surface and will be observed in particulate matter samples. The chemical analysis results indicate, that the mass distribution of the carbonaceous matter matches the volume distribution of the aerosol. The mass distribution of chemisorbed sulphate, however, follows the surface distribution of the aerosol, which was calculated from aerosol size spectra assuming a spherical particle shape (PUXBAUm et al., 2003). This observation indicates that the sulphate is chemisorbed at the particle surface. The chemisorbed fraction of sulphuric acid corresponds to a coverage of max. 0.1 monolayer in the high FSC case. This fraction of converted S(VI) is less than $0.1 \%$ of total S(IV), present in the fuel. The overall partitioning of sulphur-containing species at $150^{\circ} \mathrm{C}$ is: 97 $\% \mathrm{SO}_{2}, \leq 2.7 \%$ gaseous $\mathrm{H}_{2} \mathrm{SO}_{4},<0.3 \%$ chemisorbed. After cooling to environmental temperatures, the gas phase sulphuric acid can condense and cover the combustion particles with about one monolayer of sulphuric acid on average (HITZENBRGER et al., 2003a).

\subsection{Particle hygroscopic properties}

Particle hygroscopic properties were measured at ambient conditions using a Hygroscopicity Tandem Differential Mobility Analyser (H-TDMA) system (GYSEL et al., 2003a, 2003b). The instrument measures the hygroscopic growth factor $(\mathrm{g})$ of particles with initial dry sizes $\mathrm{D}_{o}=30,50$ and $100 \mathrm{~nm}$ over the range $\mathrm{RH} \sim 70-95 \%$ where $g(\mathrm{RH})=\mathrm{D}(\mathrm{RH}) / \mathrm{D}_{o}$. Growth factors were found to increase with increasing FSC at fixed particle size (e.g. $\mathrm{D}_{o}=50 \mathrm{~nm} ; \mathrm{g}(95 \%)=1.01$ and 1.16 for $\mathrm{FSC}=$ low and high, respectively), and to decrease with increasing particle size at fixed FSC (e.g. mid FSC; g $(95 \%)=$ $1.14,1.10$ and 1.03 for $\mathrm{D}_{o}=30,50$ and $100 \mathrm{~nm}$, respectively). The results suggest an increasing amount of sulphuric acid adsorbed on combustion particles from the gas phase with increasing FSC.

Cloud condensation nuclei $(\mathrm{CCN})$ were measured in the diluted line using a static thermal diffusion type CCN counter (GIEBL et al., 2002). Particles are exposed to controlled supersaturations of water vapour, which enables some of the particles to become activated and

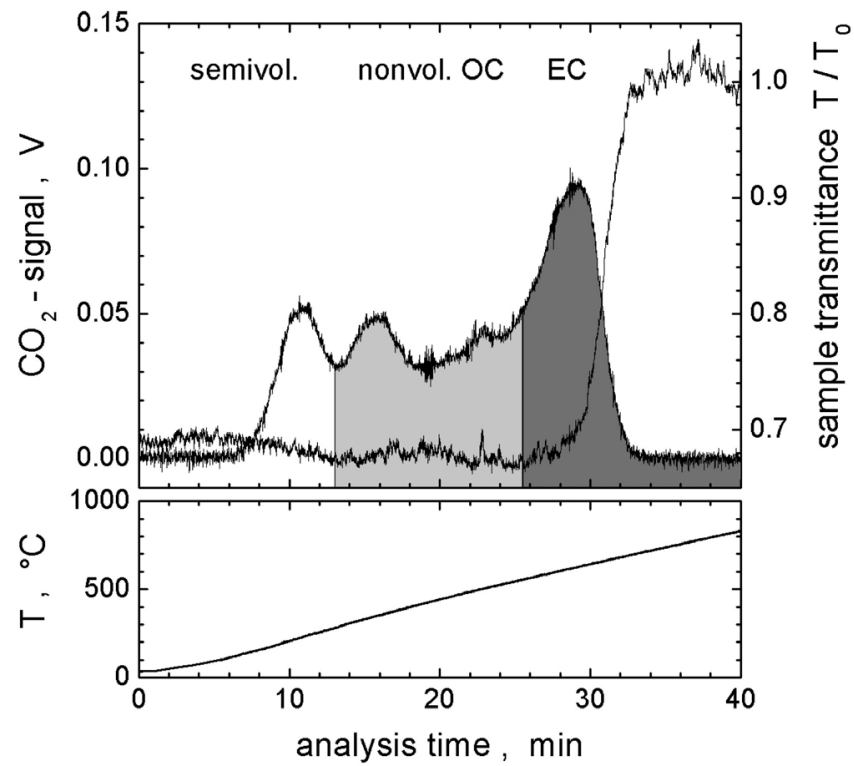

Figure 5: Evolving $\mathrm{CO}_{2}$ as a function of the sample heating temperature for a Combustor aerosol sample; semi-volatile OC oxidises at $450 \mathrm{~K}$, non-volatile OC at $600 \mathrm{~K}$, and elemental carbon above $700 \mathrm{~K}$.

grow to large $(>10 \mu \mathrm{m})$ droplets. During PartEmis, the supersaturation was set to $\sim 0.7 \%$. The fraction of $\mathrm{CCN}$ in the aerosol (relative to the concentration of particles of $D>10 \mathrm{~nm}$ ) increases with increasing FSC, but even for low FSC the fraction of CCN (at $0.755 \%$ supersaturation) is higher than the fraction of particles with diameters larger than $280 \mathrm{~nm}$, i.e. the size at which wettable insoluble particles are activated according to the Kelvin effect. At high FSC, the fraction of CCN increases by about a factor 5.5 for old and 12 for modern conditions. However, pure sulphuric acid particles of the same size, which become activated according to KÖHLER theory would give an activation ratio which is still larger by a factor $\sim 15$ compared to the observations even at high FSC. Thus, the KÖHLER model cannot reproduce measured activation properties. This is in agreement with the fact that large combustion particles are not at all completely water soluble. The Kelvin model provides good predictions for the low FSC level, but activation diameters (ratios) are increasingly overestimated (underestimated) at medium and high FSC. This indicates that the soluble fraction of the combustion particles increases from low values at low FSC level to relatively large values at high FSC. An empirical coated sphere model, which equates the measured volatile and semivolatile fraction with soluble sulphuric acid, underestimates the activation diameter by 45 to $55 \%$ under all conditions. A small amount of semivolatile organics with low or absent water-solubility adsorbed on the combustion particles might be one reason for this discrepancy. Further details are given by HitzenBERGER et al. (2003a, 2003b). 


\subsection{Gaseous hydrocarbon emission}

More than 100 different non-methane volatile organic compounds (NMVOCs), such as non-methane hydrocarbons (NMHCs) and selected partially oxidised hydrocarbons (OHCs) emitted from the aircraft engine combustor and the hot end simulator (HES) were identified and quantified. These species accounted for up to 91 wt $\%$ of the total hydrocarbons (THCs). The NMHC emission indices of $5-15 \mu \mathrm{g} \mathrm{kg}^{-1}$ in total are comparable with the AEROTRACE (Measurement of Trace Species in the Exhaust from Aero Engines, EC project AERA-CT94-0003, 1994-1997, Co-ordinated by QinetiQ) study. Both studies show up to 1000 times lower emission indices in comparison with emissions from vehicular traffic. The influence of the operation conditions on NMHC emissions of the combustor and HES was investigated for the identified NMHCs. From the six conditions which were investigated (2 operation conditions, 3 HES pressure stages), most compounds show a decrease of NMHC emissions with increasing combustion temperature at the same pressure stage. This is in agreement with results from the combustor exit measurements and with the results of the AEROTRACE study. Emission indices at HES pressure stages high (HP)-, intermediate (IP)- and low pressure (LP) for fixed FSC and combustor operation conditions were also investigated. Most compounds show a decrease of NMHC emissions with decreasing pressure in the HES at similar combustor operation conditions and fixed FSC. The decrease of the pressure in the HES corresponds to an increase of the residence time in a turbine and indicates a decrease of NMHC emissions along the different turbine sections.

\subsection{Emission of ions and charged soot particles}

The ions measured during the HES campaign (HAVERKAMP et al., 2004; Wilhelm et al., 2004) are product ions formed from primary ions via ion molecule reactions involving either few reaction-steps with massive neutral molecules or numerous reaction-steps with relatively small neutral molecules. Their lifetimes with respect to ion-ion recombination are around $9 \mathrm{~ms}$ after the high pressure turbine section. The ion emission index $E_{i}$ is up to $4.5 \times 10^{16}$ ions per $\mathrm{kg}$ fuel burnt. As is discussed by HAVERKAMP et al. (2004), neither ion-ion recombination nor ion removal by attachment to combustion particles give sufficient explanations for the observed ion emission index. Therefore, detailed model calculations of the ion chemistry taking place in the combustor with particular emphasis on the sulphur species effect is required (HAVERKAMP et al., 2004). It seems that ion-induced nucleation can explain at least partly the observed volatile aerosols. Electrically charged small positive and negative soot particles
(CSP) have also been detected during both PartEmis campaigns. Charged soot particles are found to have diameters around $6 \mathrm{~nm}$ and a total concentration of up to $4.5 \times 10^{7} \mathrm{~cm}^{-3}$ (positive and negative) corresponding to a total emission index of $E_{C S P}=2.3 \times 10^{15} \mathrm{CSP}$ per $\mathrm{kg}$ fuel burnt (WILHELM et al., 2004).

A model which considers the formation and evolution of combustion ions in a combustor of an aircraft engine in dependence on the electron detachment efficiency from negative ions was used to consider the effect of the transformation of primary negative ions to more stable secondary negative ions (SOROKIN et al., 2003). The formed stable negative ions most probably are sulphur-bearing ions. This effect slows down the charged particle neutralisation rate leading to an increase of the concentration of positive and negative ions at the combustor exit. The results of the simulation and their comparison with the ground-based experimental data obtained within PartEmis support the hypothesis, that the increase of the fuel sulphur content leads to an increase of the ion concentration at the combustor exit.

\subsection{OH measurements}

The concentration of $\mathrm{OH}$ which is the dominant oxidant in the exhaust gas was detected by laser induced fluorescence (LIF) to obtain an absolute $\mathrm{OH}$ concentration measurement in order to aid in the modelling of $\mathrm{SO}_{3}$ production from the combustor to the engine exit. When running the laser at low laser energies, $\mathrm{OH}$ in the exhaust duct was successfully detected. Calibration experiments provide a method to assign the observed OH LIF signals an absolute concentration, and from an estimate or measurement of the errors for each parameter, an overall estimate of the error in the assigned $\mathrm{OH}$ concentration was made. From these calibration experiments very low values of less than 1 ppbv were calculated for the $\mathrm{OH}$ concentration in the exhaust gas after exiting the HES. Previous experiments using a combined Raman scattering/LIF technique to look in the exhaust gases $50 \mathrm{~cm}$ behind an aircraft engine exit failed to detect any $\mathrm{OH}$ LIF signal, and therefore could only infer an upper limit for $\mathrm{OH}$ of $80 \mathrm{ppbv}$ based on the measured detection limit of their apparatus.

\section{Summary and conclusions}

The progress made during PartEmis is manifold. The main conclusions are therefore grouped into different subject areas and presented as brief statements. For each subject area key references are identified, if available.

\subsection{Combustion aerosol}

Refer to Wilson et al. (2004) and Petzold et al. (2003a): 
(i) The combustor behaves like a typical aircraft engine combustor with respect to thermodynamic data and main emissions. It may thus be expected that the PartEmis database can be applied as a first order approximation to contemporary aircraft engines.

(ii) The BC concentration is nearly independent of FSC level.

(iii) The number size distribution of primary particles in the diameter range $10<D<550 \mathrm{~nm}$ is almost uninfluenced by the FSC level or combustor conditions. At high FSC levels the formation of volatile condensation particles with diameters $D<10 \mathrm{~nm}$ occurs.

(iv) The volatile volume fraction of particles $>50 \mathrm{~nm}$ increases from $2 \%$ for low FSC to approx. $5 \%$ for high FSC. The volatile volume fraction of particles $<30 \mathrm{~nm}$ is $\leq 15 \%$.

(v) Volatility measurements indicate an internally mixed aerosol for particles with $D>15 \mathrm{~nm}$; condensation particles are below $15 \mathrm{~nm}$ in diameter.

\subsection{Ultrafine particles}

Refer to Petzold et al. (2003a) and VAnCASSEl et al. (2004):

(vi) Formation of condensation particles of size $D=$ $4-7 \mathrm{~nm}$ is observed in the Combustor tests for high FSC at old and modern conditions; formation occurs if the surface area of the combustion aerosol falls below a certain threshold limit; the observed number of formed particles is confirmed by kinetic model studies.

(vii) Formation of condensation particles is observed in the HES tests for high FSC/modern conditions/low pressure section only; the "formation strength" in terms of number of condensation particles per number of combustion particle is twice as high as for the Combustor case.

(viii) The model studies indicate that condensation particles are not emitted from the combustor but form in the sampling line at the sample dilution point.

(ix) Ultrafine carbonaceous particles of size $7 \mathrm{~nm}$ $<D<20 \mathrm{~nm}$ are observed independently of the fuel sulphur content; a volatility analysis indicates that these particles are nonvolatile and may be composed of carbonaceous compounds.

\subsection{Sulphate-containing species, chemi-ions and $\mathrm{OH}$}

Refer to KATRAGKOU et al. (2004) and HAVERKAMP et al. (2004):

(x) S(VI) was measured in the form of sulphuric acid. Increased FSC results in higher S(VI) concentrations. The measured conversion efficiency for fuel sulphur to $\mathrm{S}(\mathrm{IV})$ at the combustor exit varies from $0.35-1.4 \%$ and is independent of the investigated combustor operation conditions and FSC levels. (xi) 10-30\% of sulphate is chemisorbed on primary particles; the coverage of primary particles is below 0.1 monolayers of sulphuric acid at $150^{\circ} \mathrm{C}$ and approximately one monolayer at $25^{\circ} \mathrm{C}$.

(xii) Sulphur partitioning at $150^{\circ} \mathrm{C}: 97 \% \mathrm{SO}_{2}$, $\leq 2.7 \%$ gaseous $\mathrm{H}_{2} \mathrm{SO}_{4},<0.3 \%$ chemisorbed.

(xiii) Positive and negative gaseous ions were detected in the exhaust of a combustor, with mass numbers up to 1500 . The total ion emission index at the HES hp stage is as high as $5.4 \times 10^{17}$ positive and negative ions per kg fuel burnt. Large ions with mass numbers exceeding 4500 contribute about $10 \%$ to the total ion number concentration.

(xiv) $\mathrm{OH}$ concentration in the exhaust gas after exiting the HES is $<1$ ppbv.

\subsection{Hygroscopic growth and $\mathrm{CCN}$ activation}

Refer to GySEL et al. (2003a) and HitZENBERGER et al. (2003a):

(xv) Small differences in particle hygroscopicity are observed between old and modern cruise conditions.

(xvi) Strong effect of the fuel sulphur content is observed, particle hygroscopicity increases distinctly with increasing FSC.

(xvii) No significant effect of the HES at low and mid FSC level is observed compared to the combustor exit; an increased particle hygroscopicity downstream the HES compared to the combustor is observed at high FSC, indicating continuing transformation of S(IV) to $\mathrm{S}(\mathrm{VI})$ during the transfer through the HES.

(xviii) CCN activation of combustion particles increases with increasing FSC as a result of larger particle hygroscopicity; additional effects of adsorbed organic matter cannot be excluded.

\subsection{Gaseous organic fraction}

(xix) More than 100 different NMVOCs (aliphatic and aromatic hydrocarbons, carbonyls and acids) were identified and quantified, they account for $91 \mathrm{wt} \%$ of the total detected compounds.

(xx) A decrease in NMHC emissions from old to modern conditions at fixed HES pressure stage and fuel sulphur content (FSC) is found.

(xxi) A decrease of NMHC emissions with decreasing pressure in the HES at fixed combustor operation conditions and FSC is observed.

(xxii) No clear influence on the NMHC emissions with changing FSC at the same combustor operation condition is observed.

(xxiii) High EI's for organic acids are found. Possible explanations are that organic compounds fixed at the sampling line walls are oxidised by the hot exhaust gases, or that the acids are fixed at the surface of the soot particles, which are also trapped in the sampling cartridges. 


\subsection{Emission properties}

Refer to Wilson et al. (2004) and Petzold et al. (2003a):

(xxiv) Emission properties regarding combustion aerosol mass, number and size are determined by the combustor; the influence of the Hot End Simulator is weak.

(xxv) The processing of exhaust gas and particles during the transfer through the Hot End Simulator increases the particle hygroscopicity and formation strength of condensation particles; both effects are related to gaseous sulphuric acid.

The experimental overview of the EU PartEmis project presents the first comprehensive aerosol and gas measurements to be conducted on an aircraft engine combustor test-rig. The database will be used for further analyses as well as for plume modelling studies of the effect of aviation-related particle emissions on the global atmosphere and climate.

\section{Acknowledgements}

The PartEmis project was funded by the European Commission under contract no. G4RD-CT-2000-00207. The authors are very grateful to the test rig operation crew at QinetiQ for their very strong support during the experiments.

\section{References}

Anderson, B.E., W.R. Cofer, D.R. BAgWell, J.W. BArRick, C.H. Hudgins, K.E. Brunke, 1998: Airborne observations of aircraft aerosol emissions I: Total nonvolatile particle emission indices. - Geophys. Res. Lett. 25, 1689-1692.

BOUCHER, O., 1999: Influence of air traffic on cirrus occurrence, Nature. - 397, 30-31.

BROCK, C.A., F. SCHRÖDER, B. KÄrChER, A. PETZOLD, R. BUSEN, M. FIEBIG, 2000: Ultrafine particle size distributions measured in aircraft exhaust plumes. - J. Geophys. Res. 105, 26555-26567.

CACHiER, H., M.P. BREMOND, P. Biat-MÉnARD, 1989: Determination of atmospheric soot carbon with a simple thermal method. - Tellus, 41B, 379-390.

DeMott, P.J., Y. Chen, S.M. Kreidenweis, D.C. Rogers, D.E. SHERMAN, 1999: Ice formation by black carbon particles. - Geophys. Res. Lett. 26, 2429-2432.

Giebl, H., A. Berner, G. Reischl, H. PuXbaum, A. KASPER-GIEBL, R. HITZENBERGER, 2002: CCN activation of oxalic and malonic acid test aerosols with the University of Vienna cloud condensation nuclei counter. - J. Aerosol Sci. 33, 1623-1634.

GYSEL, M., E. WEINGARTNER, U. BALTENSPERgER, 2002: Hygroscopicity of aerosol particles at low temperatures. 2. Theoretical and experimental hygroscopic properties of laboratory generated aerosols. - Environ. Sci. Technol. 36, 63-68.
Gysel, M., S. Nyeki, E. Weingartner, U. Baltensperger, H. Giebl, R. Hitzenberger, A. PetZOLD, C.W. WILSON, 2003a: Properties of jet engine combustor particles during the PartEmis experiment. Hygroscopicity at subsaturated conditions. - Geophys. Res. Lett. 30, 1566, DOI:10.1029/2003GL016896.

GYSEL, M., S. NyeKi, E. Weingartner, U. BALtensperger, H. Giebl, R. Hitzenberger, A. PetZOLD, C.W. WILSON, 2003b: Jet engine combustion particle hygroscopicity under subsaturated conditions during PartEmis. - J. Aerosol Sci. 34 (Suppl. 2), Abstracts of the European Aerosol Conference, S1415-S1416.

Hagen, D.E., P.D. Whitefield, H. Schlager, 1996: Particle emissions in the exhaust plume from commercial jet aircraft under cruise conditions. - J. Geophys. Res. 101, 19,551-19,557.

HAGEN, D.E., P.D. Whitefield, J. Paladino, M. TrueBLOOD, H. LILENFELD, 1998: Particle sizing and emission indices for a jet engine exhaust sampled at cruise. - Geophys. Res. Lett. 25, 1681-1684.

HAGEN, D.E., P.D. Whitefield, J.D. Paladino, O. SCHMID, 2001: Comparative study of jet engine combustion emissions and engine operating conditions. In: Schumann, U., G. Amanatidis (Eds), Aviation, aerosols, contrails and cirrus clouds, Air pollution research report 74, 106-110, European Commission, Brussels.

HaVerkamp, H., S. Wilhelm, A. Sorokin, F. ARnold, 2004: Positive and negative ion measurements in jet aircraft engine exhaust: concentrations, sizes and implications, for aerosol formation. - Atmos. Environ. 38, 2879-2884.

Hitzenberger, R., H. Giebl, A. Petzold, M. Gysel, S. Nyeki, E. Weingartner, U. BALTENSPERgER, C.W. Wilson, 2003a: Properties of jet engine combustor particles during the PartEmis experiment. Hygroscopic properties at supersaturated conditions. - Geophys. Res. Lett. 30, 1779, DOI:10.1029/2003GL017294.

HitZenberger, R., H. Giebl, A. Petzoild, M. Gysel, S. Nyeki, E. Weingartner, U. BALtensperger, C.W. WILSON, 2003b: CCN activation of jet engine combustor particles during PartEmis. - J. Aerosol Sci. 34 (Suppl. 2), Abstracts of the European Aerosol Conference, S1409-S1410.

HuRLEY, C.D. 1996: AEROTRACE, Measurements of Particulates from an Engine Combustor. - Proceedings, Impact of Aircraft Emissions upon the Atmosphere, Vol 1, 113, International Colloquium, Paris, October 1996.

Katragkou, E., S. Wilhelm, F. Arnold, C.W. WilSON, 2004: First gaseous Sulfur (VI) measurements in the simulated internal flow of an aircraft gas turbine engine during project PartEmis. - Geophys. Res. Lett. 31, 2117, DOI:10.1029/2003GL018231.

NYEKI, S., M. GYSEL, E. Weingartner, U. BALtensperger, R. Hitzenberger, A. Petzold, C.W. WILSON, 2003: Volatile properties of jet engine combustor particles during PartEmis. - J. Aerosol Sci. 34 (Suppl. 2), Abstracts of the European Aerosol Conference, S1411S1412.

Petzold, A., F.P. Schröder, 1998: Jet engine exhaust aerosol characterization. - Aerosol Sci. Technol. 28, 62-76.

Petzold, A., A. DöPelheuer, C.A. Brock, F.P. SCHRÖDER, 1999: In situ observations and model calcula- 
tions of black carbon emission by aircraft at cruise altitude. - J. Geophys. Res. 104, 22171-22181.

Petzold, A., C. Stein, S. NYEKI, M. Gysel, E. Weingartner, U. Baltensperger, H. Giebl, R. Hitzenberger, A. DöPelheuer, S. VRChOticky, H. PuXbaum, M. Johnson, C.D. Hurley, R. MARsh, C.W. Wilson, 2003a: Properties of jet engine combustor particles during the PartEmis experiment. Microphysical and chemical properties. - Geophys. Res. Lett. 30,1719, DOI:10.1029/2003GL017283.

PETZOLD, A., C.W. Wilson, U. BALTENSPERger, M. Fiebig, L. Fritzsche, H. Giebl, M. Gysel, R. Hitzenberger, C.D. Hurley, S. Nyeki, H. Puxbaum, U. Schumann, C. Stein, S. Vrochticky, 2003b: Particle emissions from aircraft engines - an overview of the European project PartEmis. - J. Aerosol Sci. 34 (Suppl. 2), Abstracts of the European Aerosol Conference, S1405-S1406.

Petzold, A., A.E. Vrtala, M. Fiebig, F. Fritzsche, Ph. Mirabel, S. Nyeki, X. Vancassel, C.W. WilSON, 2003c: Emission of volatile and non-volatile ultrafine particles from a combustion source during PartEmis. - J. Aerosol Sci. 34 (Suppl. 2), Abstracts of the European Aerosol Conference, S1407-S1408.

PuXbaum, H., S. VRchoticky, A. Petzold, R. HitZenBerger, S. NyeKI, C.W. Wilson, 2003: Chemical composition of jet engine combustor particles during PartEmis. - J. Aerosol Sci. 34 (Suppl. 2), Abstracts of the European Aerosol Conference, S1413-S1414.

Schmid, H., L. Laskus, H.-J. Abraham, U. BaLTENSPERGER, V. LAVANCHY, M. BIZJAK, P. BURBA, H. Cachier, D. Crow, J. Chow, T. Gnauk, A. Even, H.M. TEN Brink, K.-P. Giesen, R. Hitzenberger, C. Hueglin, W. Maenhaut, C. Pio,.A. Carvalho, J.-P. Putaud, D. TOOM-SAuntry, H. Puxbaum, 2001: Results of the "carbon conference" international aerosol carbon round robin test stage I. - Atmos. Environ. 35, 21112121.
Schröder, F., C. Brock, R. BAumann, A. Petzold, R. Busen, P. Schulte, M. Fiebig, 2000: In-situ studies on volatile jet exhaust particle emissions: Impact of fuel sulfur content and thermodynamic conditions on nuclei-mode aerosols. - J. Geophys. Res. 105, 19941-19954.

SCHumann, U., 1996: Contrail formation from aircraft exhausts. - Meteorol. Z. N.F. 5, 4-23.

SCHUMANN, U., J. STRÖM, 2001: Aviation impact on atmospheric composition and climate. - In: European research in the stratosphere 1996-2000, European Commission, EUR 19867, Brussels.

Schumann, U. , F. Arnold, R. Busen, J. Curtius, B. Kärcher, A. Kiendler, A. Petzold, H. Schlager, F. SCHRÖDER, K.-H. WOHLFROM, 2002: Influence of fuels sulphur on the composition of aircraft exhaust plumes: The experiments SULFUR 1-7. - J. Geophys. Res. 107 (10.1029/2001JD000813), AAC 2-1 - AAC 2-27.

Sorokin, A., P. Mirabel, F. ARnold, 2003: On the Influence of fuel fulfur induced stable negative ion formation on the total concentration of ions emitted by an aircraft gas turbine engine: Comparison of model and experiment. - Atmos. Chem. Phys. 3, 6001-6018.

Vancassel, X., A. Sorokin, P. Mirabel, A. Petzold, C.W. WILSON, 2004: Volatile particles formation during PartEmis: a modelling study. - Atmos. Chem. Phys. 4, 439447.

Wilhelm, S., H. HaVerkamp, A. Sorokin, F. ARnold, 2004: Detection of very large ions in aircraft gas turbine engine combustor exhaust:charged small soot particles? Atmos. Environ. 38, 4561-4569.

Wilson, C.W., A. Petzold, S. Nyeki, U. Schumann, R. ZELLNER, 2004: Measurement and Prediction of Emissions of Aerosols and Gaseous Precursors from Gas Turbine Engines (PartEmis): An Overview. - Aerosp. Sci. Technol. 8, 131-143. 